\title{
ENTRE COOPERAÇÃO E CENTRALIZAÇÃO Federalismo e políticas sociais no Brasil pós-1988
}

\author{
José Angelo Machado \\ Universidade Federal de Minas Gerais (UFMG), Belo Horizonte-MG, Brasil. E-mail: joseangelo@fafich.ufmg.br
}

\section{Pedro Lucas de Moura Palotti}

Universidade de Brasília (UnB), Brasília - DF, Brasil. E-mail: pedro.palotti@enap.gov.br

DOI: http//dx.doi.org/10.17666/308861-82/2015

\section{Introdução}

Passadas duas décadas e meia da promulgação da Constituição federal de 1988, anuncia-se promissor o intento de revisitar problemas que pautaram as primeiras e fundadoras abordagens que caracterizaram o federalismo brasileiro no período pós-redemocratização. Partindo do debate sobre a pertinência e as características da descentralizaçáo (Arretche, 199b), passando pela análise do federalismo cooperativo como chave para interpretar a distribuição de competências nas políticas sociais (Almeida, 2000), chegando até a discussão sobre os mecanismos de coordenação federativa (Arretche, 2004; Abrucio, 2005) e a recentralização da federação, notadamente a partir de meados dos anos de 1990 (Almeida, 2005; Arretche, 2009 e 2010), além de outros pontos igualmente relevantes.

Artigo recebido em 01/07/2013

Aprovado em 28/11/2014
Neste trabalho nos propomos a analisar evidências empíricas relativas às relações intergovernamentais nas principais áreas de políticas sociais - saúde, educação e assistência social - a fim de discutir em que medida elas seriam consistentes com parâmetros típicos de um federalismo descentralizado e cooperativo (Almeida, 2000 e 2005). Partindo dos constrangimentos constitucionais e legais mais relevantes para atuação dos governos subnacionais, as referidas evidências incluem os sistemas de transferência financeira intergovernamentais, o funcionamento das comissōes intergovernamentais de caráter federativo no âmbito da gestão setorial e, por fim, a evolução de parcerias intergovernamentais por meio de consórcios públicos.

Ao final concluímos que, a despeito de o compartilhamento de competências entre esferas de governo apontar para o federalismo cooperativo, não se pode afirmar que seus atributos sejam dominantes na produção de coordenação intergovernamental nas 
áreas estudadas. A despeito de avanços relevantes na concretização de instrumentos de cooperação, como os consórcios públicos, as evidências apresentadas endossam a proposição de que são as políticas e os programas sociais formulados a partir da União, e implementados pelos governos subnacionais sob a sua regulação (Arretche, 2009 e 2010), que organizam e dão consistência às ações governamentais nessas áreas. Concentrando receitas e recursos institucionais para o exercício da coordenação federativa, a União ocupou o espaço aberto a partir do parágrafo único do artigo 23 da Constituição federal de 1988, que previa Leis complementares para fixar normas de cooperação entre as três esferas de governo. Senão por meio de Leis complementares genéricas, ${ }^{1}$ aconteceu por meio de leis ordinárias ou normas infralegais nos marcos de cada politica setorial, opção que pode, inclusive, ter conferido maior funcionalidade e adaptabilidade a condições específicas.

O trabalho está organizado da seguinte forma: na próxima seção discutimos problemas conceituais que poderiam levar a uma falsa correspondência entre compartilhamento de responsabilidades e cooperação intergovernamental. Em seguida, identificamos características do modo como tal compartilhamento se configurou no caso brasileiro, especificamente nas três áreas de políticas públicas sociais a serem tratadas: saúde, educação e assistência social. Na seção seguinte apresentamos um balanço dirigido a quatro mecanismos de coordenação federativa que afetam estes setores: garantias e constrangimentos do sistema constitucional e legal; incentivos proporcionados pelas transferências condicionadas; compartilhamento de decisões operacionais nas comissões intergovernamentais de caráter federativo; e parcerias voluntárias abordadas em consórcios intergovernamentais. Por fim, considerando a configuração geral dos elementos apresentados, retomamos o problema inicial para construir conjecturas e considerações finais.

\section{Compartilhamento de responsabilidades e cooperação}

Em sentido geral, políticas sociais trazem à luz os problemas da coordenação federativa. Eles se originam, em grande parte, da tensão constitutiva entre o caráter uniforme das garantias sociais nacionais e a preservação das diversidades regionais (Obinger et al., 2005). Na medida da variação do grau de interdependência entre escolhas dos entes governamentais, nas diferentes políticas públicas, coloca-se a necessidade de coordenação entre suas açôes, a fim de assegurar resultados coletivos minimamente consistentes. Tal coordenação pode resultar de constrangimentos legais, incentivos financeiros ou parcerias que produzam convergência na direção de tais escolhas, seja no sentido de realizar objetivos fixados no plano nacional, seja de eliminar irracionalidades decorrentes da superposição ou da inexistência de iniciativas.

Uma das condições que afeta a capacidade de coordenação federativa diz respeito ao modo como são distribuídas as responsabilidades por políticas públicas entre esferas de governo. Neste ponto existem focos de convergência salientes na propositura de critérios de classificação ou tipologias. Em uma delas, a Advisory Commission on Intergovernmental Relations - ACIR ${ }^{2}$ (1981) contrapõe, como formas ideais, os federalismos dual, cooperativo e centralizado. No federalismo dual, os poderes do governo nacional e dos estados, embora incidindo sobre o mesmo território, atuam separada e independentemente dentro das respectivas jurisdiçôes ou setores de políticas públicas sob sua responsabilidade. No federalismo cooperativo, haveria um compartilhamento intergovernamental destas mesmas jurisdições, quebrando o nítido padrão de separação de autoridade e responsabilidade exclusiva entre governo nacional e dos estados. ${ }^{3}$ Já no federalismo centralizado, estes últimos se tornariam meros agentes administrativos do governo nacional, detentor de poder regulamentador e de recursos para atuação daqueles. Por outro lado, Scharpf (1988) se vale da contraposição entre o modelo norte-americano e o alemão quanto à forma de alocar autoridade sobre as áreas da ação governamental: no primeiro, as diferentes esferas de governo detêm autoridade independente sobre políticas públicas ${ }^{4}$, sendo possível caracterizá-lo a partir do peso relativo de cada área; no segundo, a autoridade sobre uma mesma área é compartilhada entre diferentes esferas. Obinger et al. (2005) e Broschek (2007), por sua vez, se valem da distinção entre federalismo inter e intraestado. No primeiro, há uma divisão vertical 
de poder bem estabelecida, sendo as competências sobre diferentes políticas públicas distribuídas entre as esferas de governo. No segundo, essas competências são compartilhadas, havendo uma divisão apenas funcional de tarefas entre tais esferas, geralmente cabendo à União a formulação e a coordenação; às unidades subnacionais, a implementação.

Nessas tipologias, o critério que permite identificar as variaçōes é a atribuição de jurisdição sobre áreas de governo, sendo relevante seu caráter exclusivo ou compartilhado. Desse ponto de vista, há similaridade entre as categorias federalismo dual, modelo norte-americano e o federalismo interestado, que remetem às situaçôes em que a cada esfera de governo corresponde a responsabilidade por uma determinada área de governo. De sua parte, as categorias federalismo alemão e o intraestado apontam em direção aos casos em que uma mesma área de governo está sob responsabilidade compartilhada entre diferentes esferas, dependendo portanto da articulação entre suas açōes. De sua parte, tanto o federalismo cooperativo quanto o centralizado poderiam ser aqui encaixados, embora ofereçam soluçôes distintas para a produção da referida articulação: no caso do primeiro, a partir de uma ação conjunta e previamente concertada entre os envolvidos, detendo os governos subnacionais autonomia e capacidade financeira; no caso do último, a partir de iniciativas do governo nacional, dotado de recursos de indução de comportamentos dos governos subnacionais (Machado, 2008). O Quadro 1 ilustra os pontos equivalentes entre as classificaçôes sobre federalismo citadas anteriormente.
Se estivermos corretos quanto a isso, não faria sentido a presunção de identidade entre compartilhamento de responsabilidades e cooperação, ${ }^{5}$ presente na própria definição apresentada pela ACIR. $\mathrm{Na}$ mesma direção, encontramos elementos na literatura que reforçam essa disjunção. Souza (2005), ao analisar as competências concorrentes no desenho federativo brasileiro, distingue a cooperação, de um lado, como pressuposto de uma norma constitucional, na qual se prevê o compartilhamento de responsabilidades, e, de outro, como elemento factual. A despeito do compartilhamento constitucionalizado em diversas políticas públicas, a autora sugere que a cooperação poderia não se estabelecer como padrão dominante, dadas as profundas diferenças de capacidade entre governos subnacionais e a ausência de incentivos institucionais, do que resulta a emergência de comportamentos competitivos. Francese (2010) também sinaliza nesta direção ao caracterizar a Constituição de 1988 como padrão institucional híbrido, que combina compartilhamento de responsabilidades em diversas áreas governamentais com dispositivos que estimulam a competição. Por sua vez, Scharpf (1988), ao tratar do federalismo alemão após a reforma constitucional dos anos de 1960, identificou e descreveu comportamentos não cooperativos e solidários nas políticas compartilhadas. Fracassos na implementação de acordos entre governo federal e os länder para colaboração na educação primária e secundária ou a incapacidade de gerar programas nacionais conjuntos para apoiarem os länder afetados por crises econômicas externas estão entre esses casos.

Quadro 1

Correspondências entre Tipologias de Classificação sobre Federalismo

\begin{tabular}{llll}
$\begin{array}{l}\text { Jurisdição sobre áreas } \\
\text { governamentais }\end{array}$ & Tipologia Scharpf (1988) & $\begin{array}{l}\text { Tipologia Obinger } \text { et al. } \\
(\mathbf{2 0 0 5 )} \text { e Broschek (2007) }\end{array}$ & Tipologia ACIR (1981) \\
\hline $\begin{array}{l}\text { Responsabilidade de uma } \\
\text { única esfera de governo }\end{array}$ & $\begin{array}{l}\text { Federalismo } \\
\text { norte-americano }\end{array}$ & Federalismo interestado & Federalismo Dual \\
\hline $\begin{array}{l}\text { Compartilhada entre } \\
\text { diferentes esferas de governo }\end{array}$ & Federalismo alemão & Federalismo intraestado & Federalismo cooperativo \\
\cline { 1 - 3 } & & Federalismo centralizado \\
\hline
\end{tabular}

Fonte: Elaboração própria. 
Assim, sendo o compartilhamento constitucional de responsabilidades um atributo compatível, ao mesmo tempo, com um padrão cooperativo ou com um padrão centralizado, parece-nos relevante analisar em que medida o federalismo brasileiro estaria avançando em uma ou outra direção, em especial em áreas governamentais em que tal compartilhamento se apresenta. Seria seu padrão dominante mais próximo dos traços típicos do federalismo cooperativo em que se observa uma "ação conjunta entre instâncias de governo, nas quais as unidades subnacionais guardam significativa autonomia decisória e capacidade própria de financiamento" (Almeida, 2000, pp. 13-14)? Ou poderíamos afirmar com alguma segurança que nosso federalismo é centralizado? Há um forte movimento, na literatura política que analisa o federalismo brasileiro, que reivindica sua recentralização desde meados dos anos de 1990 e que, a despeito da preservação de espaços de autonomia para governos subnacionais, a coloca como ponto chave para explicar o sucesso na coordenação federativa das políticas públicas desde então (Arretche, 2004, 2009 e 2010; Melo, 2005). O presente trabalho propõe-se a examinar a prevalência ou não deste padrão centralizado, ainda que de forma restrita a três das principais políticas sociais - saúde, educação e assistência social - para as quais descrevemos, na próxima seção, os respectivos sistemas de compartilhamento de responsabilidades.

\section{Políticas sociais e compartilhamento de responsabilidades}

A Constituição de 1988 assegurou à União "o maior e mais importante leque de competências exclusivas" (Souza, 2005, p. 111), incluindo a defesa nacional, a política macroeconômica - no interior da qual se incluem a emissão de moeda e administração de reservas cambiais -, bem como o controle da exploração dos serviços de telecomunicação e navegação aérea, entre outros (Brasil, 2012). As políticas sociais, de modo geral, foram estabelecidas como competências comuns à União, estados e municípios, sendo definidas no campo legislativo como concorrentes a estas três esferas de governo (Almeida, 2000 e 2005; Souza, 2005; Arretche,
2004). Porém há especificidades nos esquemas de compartilhamento das competências comuns para as três áreas aqui tratadas, mesmo que sejam notáveis as aproximações, em especial entre as áreas da saúde e da assistência social. Em ambas, inclusive, foram as respectivas leis orgânicas (Leis n. 8080/1990 e $8142 / 1990$, no caso da saúde, e $8742 / 1998$, posteriormente modificada pela Lei n. 12435/2011, no da assistência social) que tornaram mais precisas as funções específicas dos entes vinculados a cada esfera no contexto dos respectivos sistemas.

No setor da saúde não há, em geral - salvo algumas exceções definidas, sobretudo, na Lei n. 8080/1990 -, exclusividade ou jurisdição própria de alguma esfera de governo sobre determinada área de atuação ou nível de atenção à saúde. $\mathrm{O}$ sistema constitucional e legal define uma estreita articulação entre União, estados e municípios, conformando um sistema "com direção única em cada esfera de governo" (artigo 198, inciso I da Constituição federal). As especificidades da atuação de cada uma delas são, claramente, mais funcionais que jurisdicionais, cabendo à União a coordenação, a normatização e a definição de padrōes nacionais para a ação governamental no setor da saúde. Aos estados foram reservadas funções de coordenação e normatização complementar na sua esfera, além de acompanhamento, avaliação e controle das redes regionalizadas do Sistema Único de Saúde (SUS), bem como apoio técnico e financeiro, enquanto aos municípios foram reservadas as de "planejar, organizar, controlar e avaliar as ações e os serviços de saúde e gerir e executar os serviços públicos de saúde" (artigo 18, inciso I da Lei n. 8080/90). Neste arranjo setorial o Executivo federal foi o agente investido de autoridade para tomar as decisões mais importantes da política pública (Arretche, 2004), não obstante a dependência da cooperação de governos subnacionais para sua materialização, uma vez que eram responsáveis diretos pela gestão das unidades e dos serviços de saúde. Merece especial atenção o fato de que o Executivo federal tenha optado por compartilhar a construção das regras para descentralização de responsabilidades e recursos com as representações nacionais de estados e municípios por meio da Comissão Intergestores Tripartite (CIT). Esta estratégia conferiu flexibilidade 
para ajustes conjunturais aos desafios colocados em diferentes momentos da implementação do SUS. Inicialmente, descentralizar a gestão das unidades e dos serviços de saúde para os municípios (Norma Operacional Básica - NOB 01/1993); em seguida, estruturar a atenção básica e os níveis de atenção à saúde subsequentes (NOB 01/1996); adiante, regionalizar as redes de atenção à saúde como estratégia para garantir integralidade e equidade no acesso (NOB 01/2002), e assim por diante.

No caso da educação, diversamente, a Constituição estabeleceu um desenho mais complexo para a distribuição de responsabilidades entre esferas de governo. Foram atribuídas competências comuns, a serem desempenhadas em regime de colaboração entre tais esferas, ao lado de competências a serem desempenhadas prioritariamente por estados e municípios, e competências privativas da União. No artigo 211 da Constituição federal ficou definido que União, estados e municípios, "em regime de colaboração", organizariam os "seus" sistemas de ensino, produzindo um desenho distinto daquele da saúde e, como veremos adiante, da assistência social, nos quais as três esferas de governo se articulam em sistemas de abrangência nacional. No primeiro parágrafo vinculado a este artigo foram descritas as competências privativas da União: organizar o sistema federal de ensino e financiar as instituiçōes públicas federais; exercer funçôes redistributivas e supletivas, a fim de assegurar equidade das oportunidades educacionais e um padrão mínimo de qualidade do ensino, prestando assistência aos estados e municípios. A estes últimos, nos parágrafos seguintes, foram atribuídas competências prioritárias: aos primeiros, o ensino fundamental e médio; aos últimos, o ensino fundamental e infantil. Para ambos, a organização dos respectivos sistemas educacionais se daria mediante formas de colaboração que assegurassem a universalização do ensino obrigatório, ou seja, o fundamental. Posteriormente, a Lei de Diretrizes e Bases da Educação (n. 9394/1996) reafirmou a autonomia dos estados e municípios na organização dos respectivos sistemas educacionais, bem como o papel regulador da União. No mesmo ano, a Lei 9424 criou um mecanismo de compartilhamento de receitas financeiras para financiamento do ensino fundamental baseado no número de matrículas em estabelecimentos de ensino dos entes federados (Fundef). Mais à frente, a Lei n. 11494/2007 regulamentou o artigo 60 das Disposições Transitórias da Constituição Federal, instituindo o Fundo de Manutenção e Desenvolvimento da Educação Básica e de Valorização dos Profissionais da Educação (Fundeb) e criando comissão intergovernamental com atribuições vinculadas ao regime de colaboração entre as três esferas de governo na sua operacionalização. Vale notar que também na educação, a despeito das mencionadas diferenças, a premissa da cooperação também subjaz à distribuição das responsabilidades entre as esferas de governo.

Por fim, o desenho da distribuição de responsabilidades entre esferas de governo na assistência social se assemelha ao adotado na saúde. Trata-se, como vimos, de um sistema único que articula os papéis desempenhados pelas três esferas de governo. Neste caso, a Constituição federal definiu como diretriz, em seu artigo 204, inciso I, a descentralização político-administrativa, cabendo a coordenação e a normatização geral à esfera federal, enquanto a coordenação e a execução dos respectivos programas ficaria a cargo das esferas estadual e municipal. Anos depois a Lei Orgânica de Assistência Social (n. 8742/1993), reafirmou que:

Art. 11. As ações das três esferas de governo na área de assistência social realizam-se de forma articulada, cabendo a coordenação e as normas gerais à esfera federal e a coordenação e execução dos programas, em suas respectivas esferas, aos Estados, ao Distrito Federal e aos Municípios.

Esta definição genérica foi detalhada pela Lei n. $12435 / 2011$, em seu artigo 24 , parágrafo $3^{\circ}$, onde se definiu que "operacionalização, prestação, aprimoramento e viabilização dos serviços, programas, projetos e benefícios" da política de assistência social seriam cofinanciados pelas três esferas de governo. Cada esfera também ficou responsável, em seu escopo de atuação, pelo monitoramento e avaliação da política de assistência social. Já a assessoria técnica deveria ser desenvolvida, no âmbito da União, em estados e municípios e, no âmbito dos estados, em municípios. Outro aspecto importante seria a obrigatoriedade da declaração de recebimento de recursos federais por parte dos estados e dos 
municípios, que prestam contas anualmente em relatório de gestão, os quais também devem comprovar a execução das ações correspondentes. Assim, também neste setor, o sistema constitucional e legal estabeleceu responsabilidades compartilhadas com funções específicas, porém articuladas de modo a conformar um único sistema nacional.

Desse modo, o compartilhamento de responsabilidades nas políticas sociais criou espaços potenciais de articulação e complementariedade das ações governamentais, porém ao preço de tornar o sucesso na implementação vulnerável ao comportamento dos governos subnacionais. Estes, dotados de autonomia político-administrativa, estariam habilitados, em última instância, a fazer escolhas e dar encaminhamentos próprios a essas políticas sob vários aspectos, nem sempre convergindo para direção das políticas nacionais. Se o compartilhamento constitucional de responsabilidades supõe a cooperação na realização dos objetivos nacionais das políticas sociais, não existem garantias, a priori, de que os entes governamentais ajustem suas açôes nessa direção. Na próxima seção analisaremos mecanismos destinados a promover tais ajustamentos.

\section{A presença do "componente cooperativo"}

Considerado o compartilhamento de responsabilidades nas políticas sociais e as precárias garantias para que governos subnacionais atuem na direção e na intensidade requerida pelos programas formulados pela União, dada sua autonomia, o alinhamento entre as três esferas dependeria de que estados e municípios assumissem a gestão das políticas públicas por iniciativa própria, por adesão às iniciativas nacionais ou por expressa imposição constitucional (Arretche, 1999a). Nesta seção examinaremos estes três caminhos, porém em ordem inversa: primeiramente, os dispositivos que impõem obrigações constitucionais e legais; em segui$\mathrm{da}$, as transferências financeiras condicionadas, que se apresentam no sentido de buscar a adesão aos programas federais e, por fim, uma das estratégias de iniciativa própria dos governos subnacionais, qual seja, os consórcios públicos. Entre o segundo e o terceiro caminho, incluímos a análise daquilo que poderia constituir uma quarta via: a constituição de arenas federativas de pactuação entre representações das esferas de governo, firmando acordos a serem encaminhados conjuntamente por todos, materializadas nas comissóes intergovernamentais de políticas públicas. ${ }^{6}$ Nossa análise será direcionada para, ao final, avaliar o nível de inserção do componente cooperativo na coordenação federativa das políticas sociais, assumindo como parâmetro deste os pressupostos explicitados por Almeida (2000) para o federalismo cooperativo definido pela ACIR (1981): ação conjunta entre instâncias de governo com significativa autonomia decisória e capacidade própria de financiamento.

\section{Constrangimentos constitucionais e legais}

A Constituição federal de 1988 e o arcabouço legal que dela se originou, além de estabelecer o compartilhamento de responsabilidades nas políticas sociais, introduziu limites e parâmetros de atuação para estados e municípios na sua implementação ou, ainda, autorizou a União a fazê-lo unilateralmente por meio de instrumentos normativos infralegais. Para efeitos deste trabalho, trataremos essas duas hipóteses, respectivamente, como constrangimentos diretos e indiretos.

Nos constrangimentos diretos o próprio texto constitucional ou leis regulamentares ou complementares definem limites ou obrigações que diminuem a margem de escolha de estados e municípios ao atuarem nas políticas sociais. Estes incluem a vinculação do gasto de receitas orçamentárias próprias a determinada área de governo, como ocorre na educação e na saúde (Arretche, 2004); critérios para uso desses recursos vinculados ou, mesmo, restrições para gastos com pessoal e endividamento, entre outros.

Considerando as três áreas governamentais analisadas neste trabalho, nota-se que a vinculação do gasto de receitas orçamentárias próprias foi estabelecida para os setores de educação e saúde, deixando de fora a assistência social. No setor educacional, o artigo 212 da Constituição federal definiu um patamar mínimo de aplicação correspondente: $18 \%$ destas para a União e $25 \%$ para estados e municípios. No setor da saúde, por meio da Emenda constitu- 
cional 29/2000, o artigo 77 estabeleceu que estados arcassem com $12 \%$ e municípios, com $15 \%$, ficando a União de corrigir anualmente o gasto realizado a partir de $2000^{7}$ pela variação nominal do Produto Interno Bruto (PIB). A vinculação do gasto de receitas próprias compromete os entes governamentais com um piso mínimo de aplicação nas duas áreas de políticas sociais, executada sob a vigilância dos órgãos de controle externo como o Tribunal de Contas da União e os dos estados. A eficácia dessa determinação, entretanto, depende do estabelecimento de critérios para classificar as despesas como próprias a cada setor, evitando manobras contábeis que facilitem o "cumprimento" dos limites para cada esfera de governo. Nas despesas com educação, segundo o artigo 213 da Constituição, "recursos públicos serão destinados às escolas públicas, podendo ser dirigidos a escolas comunitárias, confessionais ou filantrópicas, definidas em lei”, desde que não lucrativas e assegurando a destinação pública de seu patrimônio em caso de encerramento de suas atividades. No caso da saúde, somente com a Lei complementar n. $141 / 2012^{8}$ é que as despesas foram definidas como aquelas voltadas para promoção, proteção e recuperação da saúde, desde que cumprindo simultaneamente três condições: destinadas a ações e serviços de acesso universal, igualitário e gratuito; previstas nos planos de saúde de cada ente federado; e de responsabilidade específica do setor da saúde. Em que pese o caráter geral da parametrização dos gastos com educação e saúde, o fato de estados e municípios serem majoritariamente responsáveis pela implementação dessas políticas os tornam os principais destinatários desses constrangimentos. Sem entrar aqui em uma análise de mérito quanto à sua pertinência para o desenvolvimento social e equidade no plano nacional, o arranjo federativo brasileiro obriga estados a gastar pelo menos 37\% (12\% com saúde e $25 \%$ com educação) e municípios a gastar pelo menos $40 \%$ (respectivamente, $15 \%$ e $25 \%$ ) das suas receitas próprias, estando estabelecido previamente qual o tipo de despesa seria executada em cada setor.

Outro nível de restrição direta diz respeito àquelas determinações constitucionais e legais que impactam capacidades dos governos subnacionais na implementação de políticas sociais, limitando gastos com pessoal ou endividamento, por exem- plo. Neste particular, destacamos aqui as implicações da Lei de Responsabilidade Fiscal (LRF) sobre o gasto com pessoal, em vista de seus efeitos diferenciados dado o papel que estados e municípios assumem nas políticas sociais. A princípio, nota-se que LRF foi uma resposta para coordenar o comportamento fiscal dos governos no sistema federativo brasileiro (Almeida, 2005), porém seus efeitos foram muito além, ampliando o controle da União sobre o modo como estados e municípios executam suas políticas (Arretche, 2009). No caso dos gastos com pessoal, definiu que a União não poderia ultrapassar mais que $50 \%$ das receitas correntes líquidas; no caso dos estados e municípios, não mais que $60 \%$. Mas as trajetórias das diferentes esferas de governo neste ponto são bem distintas. Quanto à União, nos primeiros anos da década $2000 \mathrm{seu}$ gasto com pessoal caiu, como proporção da despesa líquida, de 31,88\%, em 2002, para 30,25\%, em 2004 (Nesp/Ceam/UnB, 2006), tendo chegado ao terceiro trimestre de 2012, último dado disponível, a 21,67\% (Brasil/Tesouro Nacional, 2012), portanto muito distante do limite. Quanto aos estados, a situação, na média, não é desconfortável: a despesa com pessoal tem caído como proporção da receita líquida, passando de $47,85 \%$ para $41,93 \%$ entre 2000 e 2004, também afastando-se do limite. Já quanto aos municípios, a situação é, na média, inversa à das demais esferas, passando de 43,52\% para $47,41 \%$, já entre 2000 e 2003 . Ora, sendo as políticas sociais áreas governamentais que mais absorvem força de trabalho nos municípios e tendo, estes últimos, assumido a maior parte das funções de implementação, são eles o principal alvo desse constrangimento constitucional e legal. Nem a União e nem os estados, ${ }^{9}$ dado seu papel coordenador e formulador, estarão pressionados a absorver grandes contingentes de força de trabalho nestas áreas governamentais e, por consequência, não deveriam ter problemas com os limites com gastos de pessoal fixados pela LRF. Os efeitos distributivos da norma geral são assimétricos; a União, inclusive, foi bem-sucedida ao relaxar outras restriçôes diretas sobre si, como na desvinculação de suas receitas, ${ }^{10}$ que lhe permitem excluir $20 \%$ de toda a arrecadação tributária das vinculaçôes constitucionais que a obrigam a alocar ou transferir recursos. 
Por outro lado, existem constrangimentos indiretos, decorrentes de poderes conferidos à União por meio de dispositivos constitucionais ou legais, autorizando-a a exercer um papel de formulação, coordenação ou supervisão nas políticas sociais. No caso da saúde, a Lei n. 8080/1990, em seu artigo 16 , reservou à União funções de formulação, coordenação (redes de assistência de alta complexidade, vigilância sanitária, vigilância epidemiológica, entre outros) e estabelecimento de normas e parâmetros nacionais (controle sanitário, relaçóes entre o poder público e setor privado contratado, sangue e hemoderivados, entre outros). No que diz respeito às transferências financeiras para "cobertura das ações e serviços de saúde a serem implementados pelos municípios, estados e Distrito Federal”, a Lei n. 8142/1990 autorizou o Ministério da Saúde, em seu artigo 5, a estabelecer as condiçôes para sua aplicação, o que passou a ser feito por via das portarias ministeriais, dando à sua burocracia especializada um recurso institucional notável. $\mathrm{Na}$ assistência social, o artigo 11 da Lei Orgânica (Lei n. 8742/1993 consolidada com a Lei n. 12101/2009) atribuiu explicitamente a "coordenação e as normas gerais à esfera federal”, embora atribua ao Conselho Nacional de Assistência Social (CNAS), órgão deliberativo colegiado ligado à administração pública federal, a coordenação da política nacional de assistência social. Se a representação neste conselho é paritária entre governo e sociedade civil, a União detém sete das nove vagas da representação governamental, o que também lhe dá uma influência diferenciada para "aprovar critérios de transferência de recursos para os estados, municípios e Distrito Federal" (artigo 18, inciso IX). Cabe ainda à União a coordenação das açôes nacionais na assistência social e a proposição da política nacional de assistência social e dos critérios de transferências de recursos ao CNAS, a expedição de atos normativos para gestão do Fundo Nacional de Assistência Social, entre outras funçôes que lhe dão poder diferenciado diante dos governos subnacionais. Já na educação, embora haja particularidades, a União também detém o papel de normatizar; formular planos nacionais; coletar, analisar e disseminar informaçôes; bem como prestar assessoria técnica para estados e municípios, exercendo "função redistributiva e su- pletiva" (artigo 211 da Constituição federal e artigo 8 da Lei n. 9394/1996). Estados e municípios poderiam "baixar normas complementares" para seus sistemas de ensino (artigos 10 e 11 da mesma lei). Além disso, o Fundo Nacional de Desenvolvimento da Educação, autarquia vinculada à Uniāo, detém fortes poderes normativos e de controle sobre governos subnacionais no que se refere às condições para repasse e execução de recursos. Desse modo, em grande parte em decorrência de sua função coordenadora e formuladora, a União concentrou, nas três áreas de políticas públicas, recursos institucionais importantes para constrangerem governos subnacionais a adotarem comportamentos compatíveis com suas iniciativas.

O sistema constitucional e legal foi estabelecido de modo a gerar constrangimentos gerais sobre todas as esferas de governo quanto ao nível de gasto nos setores de saúde e educação, bem como quanto ao gasto com pessoal, mas seus efeitos distributivos foram assimétricos, pesando bem menos sobre a União e bem mais sobre os municípios. Por outro lado, tal sistema conferiu à União recursos institucionais que, embora compatíveis com o federalismo cooperativo, lhe oferecem possibilidades estratégicas para convertê-lo em um federalismo centralizado, uma vez que induz governos subnacionais a se comportarem como "meros agentes administrativos". Este tema será retomado no próximo segmento.

\section{Transferências financeiras condicionadas}

A segunda metade dos anos de 1990 marcou uma virada em termos de recuperação da capacidade de coordenação federativa por parte da União. A conquista da estabilidade macroeconômica e a adoção de medidas progressivas de controle fiscal, com fortes restrições ao comportamento dos governos subnacionais, abriu um novo capítulo nas relações intergovernamentais. Acrescente-se aqui, ainda, o movimento do Executivo federal para recompor sua participação nas receitas públicas, vis-à-vis a dos estados e municípios, por meio das contribuições sociais e de domínio econômico, não compartilhadas obrigatoriamente com eles (Almeida, 2007; Resende e Afonso, 2004). Essas novas condições alteraram a balança de poder federativa, dando 
novos recursos de barganha para a União diante de estados e municípios, crescentemente dependentes. Tais recursos, somados às prerrogativas para exercer o papel coordenador e supervisor nos diferentes setores, descritas na seção anterior, deram à União condições para se valer de transferências financeiras condicionadas como instrumento de indução do comportamento dos governos subnacionais.

Diferentemente das transferências intergovernamentais livres, em que governos subnacionais alocam livremente os recursos recebidos, as transferências condicionadas favorecem o alinhamento das prioridades dos governos subnacionais àquelas eleitas pelo Executivo federal. A concretização das transferências dependeria, obviamente, da adesão dos últimos a programas federais, adesão esta condicionada por um cálculo que considera custos e benefícios fiscais e políticos, bem como dos recursos administrativos próprios, sendo todos esses fatores relevantes na escolha de assumir ou não a gestão de ações e serviços desenhados em âmbito federal (Arretche, 1999a). Em grande medida, as referências na literatura apontam para o sucesso da União em obter a adesão para seus programas federais, especialmente a partir da segunda metade dos anos de 1990, em diferentes áreas de políticas públicas (Arretche, 1999a, 2004; Abrucio, 2005; Almeida, 2000 e 2005), o que sugere a percepção, pelos governos subnacionais, de maiores custos e riscos ao construir e implementar uma agenda social desconectada do Executivo federal. A adesão permite contar com novas e regulares fontes de recursos, com reduzidos riscos de implementação em vista do apoio e da cooperação técnica da União e, em certos casos, dos estados. O Executivo federal reuniu, assim, condiçôes para estruturar a agenda social dos governos subnacionais sem necessidade de medidas exclusivamente coercitivas, tendo as transferências condicionadas se disseminado nas políticas sociais de uma forma geral. Uma boa indicação disso é a evolução histórica das transferências de recursos federais para estados e municípios no conjunto das despesas discricionárias da União ${ }^{11}$ entre 1995 e 2008. Estas saltaram de $18,3 \%$ para $57,7 \%$,

\section{Gráfico 1}

Participação das Modalidades Execução de Despesas Federais com Políticas Sociais entre 1995 e 2008

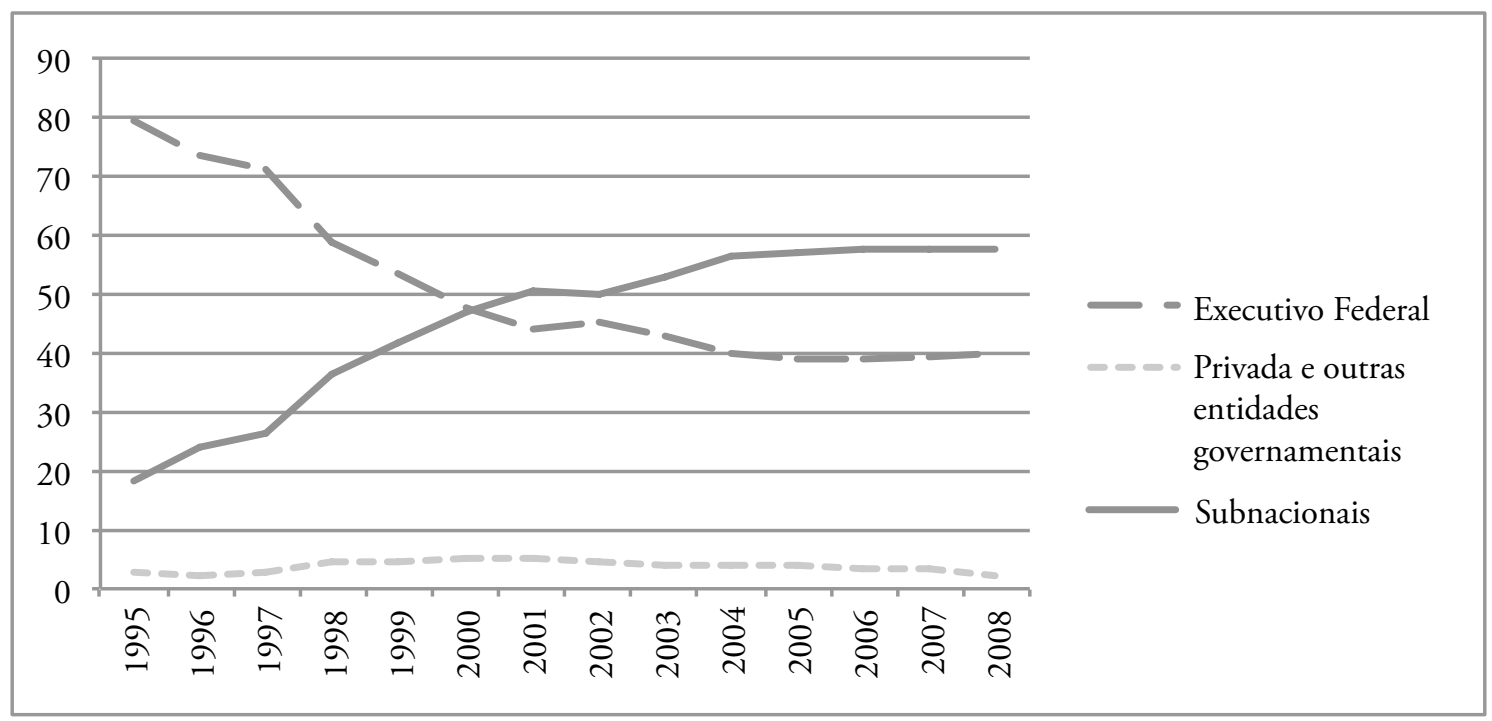

Fonte: Elaboração própria a partir dos dados disponibilizados pela SOF/Ministério do Planejamento. Disponível em https://orcamentofederal.gov.br/informacoes-orcamentarias/pasta-estatisticas-fiscais/10.-despesas-discricionarias-por-areaorgao-e-modalidade-de-aplicacao. 
enquanto a execução própria das despesas pela União ou por meio de entidades privadas e outras entidades governamentais caíram, respectivamente, de $79,2 \%$ para $40,0 \%$ e de $2,5 \%$ para $2,4 \%$. O Gráfico 1 refere-se às despesas gerais com políticas sociais, incluindo, ao lado daquelas como saúde, educação e assistência social, as despesas com esporte e lazer, cultura e trabalho e emprego.

No mesmo período, enquanto as transferências obrigatórias de receitas arrecadadas pela União, para estados e municípios, cresceram 7,09 vezes em termos nominais, transferências discricionárias para estados e municípios executarem políticas sociais cresceram 15,47 vezes. ${ }^{12}$ Como percentual da receita corrente líquida da União, as transferências obrigatórias passaram de $16,2 \%$ para $19,2 \%$ e as discricionárias subiram mais, proporcionalmente, passando de $2 \%$ para $6 \%$, conforme Gráfico 2.

Transferências discricionárias da União são formalizadas por meio de instrumentos distintos, incluindo transferências fundo a fundo de caráter universal, ${ }^{13}$ regular e com duração indefinida, além de convênios ${ }^{14}$ e contratos de repasse. ${ }^{15}$ Entre essas modalidades, chama atenção o crescimento das transferências regulares fundo a fundo, com poder estruturante diferenciado sobre a agenda social dos governos subnacionais, uma vez que configura uma fonte estável de recursos para programas sociais em um contexto de contenção fiscal (Machado, 2011). Entre 2005 e 2008, esse mecanismo abarcou, em média, 95\% das transferências discricionárias no setor da saúde, $52 \%$ na educação e $71 \%$ na assistência social. Outra questão apontada foi a constatação de que as transferências fundo a fundo regulares estruturam as relações intergovernamentais de maneira semelhante a uma relação de agência ${ }^{16}$ - concepção e desenho do programa pela União, mecanismos de controle e punição dos governos subnacionais, entre outros -, embora também subsistam elementos de compartilhamento de gestão entre as três esferas, com intensidades distintas entre as diferentes áreas de governo.

De qualquer forma, as transferências intergovernamentais condicionadas agregam novos elementos à discussão sobre o caráter do federalismo brasileiro. Detentora de recursos financeiros e poder normativo, além de burocracia especializada e recursos informacionais diferenciados, o Executivo

\section{Gráfico 2}

\section{Transferências Federais para Esferas Subnacionais Visando Políticas Sociais Perante Transferências Discricionárias e Obrigatórias entre 1995 e 2008 - em R\$ milhóes}

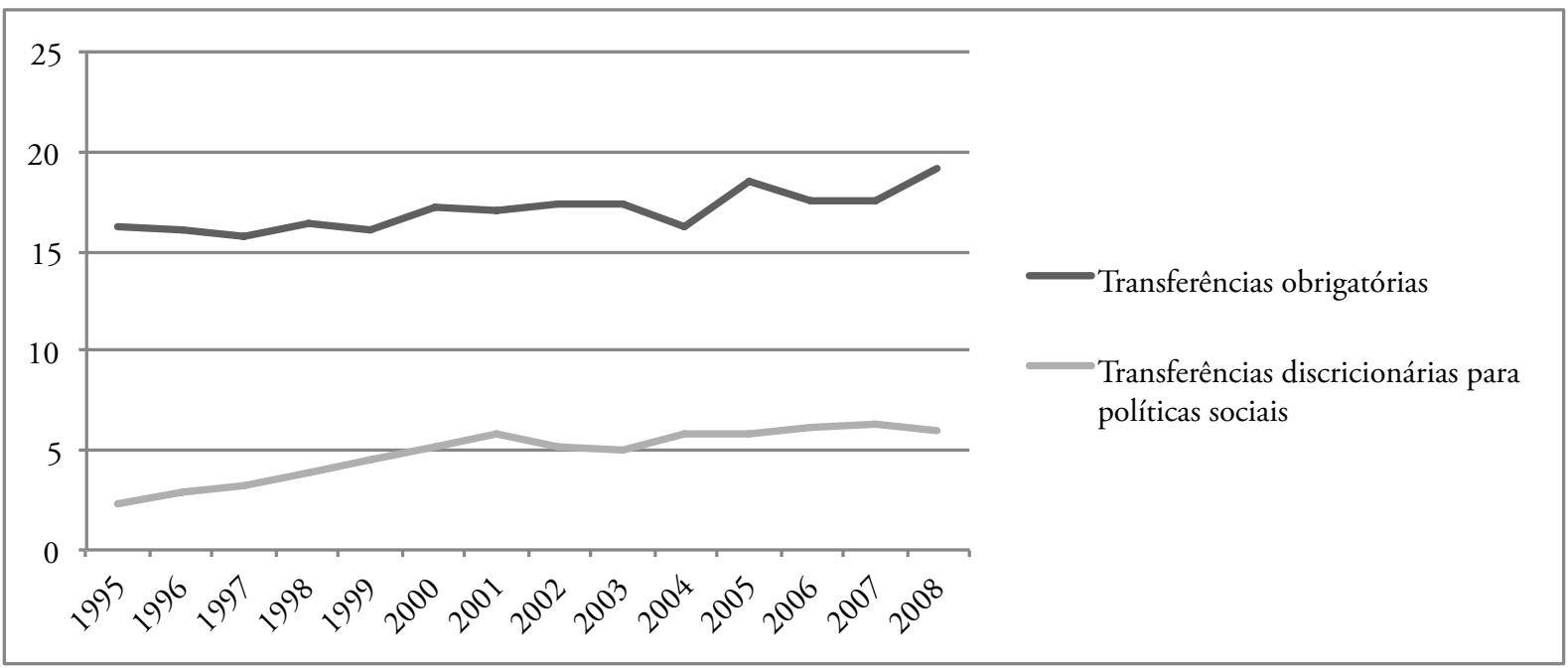

Fonte: Elaboração própria a partir dos dados disponibilizados pela SOF/Ministério do Planejamento. 
federal as adotou como estratégia privilegiada para indução da agenda social dos governos subnacionais, que sob significativas restriçôes fiscais têm aderido aos programas federais. Tal cenário converge para o federalismo centralizado, nos termos definidos pela ACIR (1981), em que governos subnacionais se comportam como agents da União; mas também, supostamente, contempla atributos do federalismo cooperativo: a configuração de arenas intergovernamentais de caráter federativo para pactuação em torno de programas, projetos e distribuição de responsabilidades e recursos entre as três esferas de governo. Nestas, para além do mero compartilhamento jurisdicional no sistema constitucional e legal, o caráter cooperativo incluiria a ação conjunta entre entes governamentais de esferas de governo distintas, porém preservadas a autonomia decisória e de financiamento de cada parte (Almeida, 2000). A seguir, analisamos seu funcionamento nas três áreas governamentais a fim de verificar a pertinência desta suposição.

\section{Comissóes intergovernamentais nas politicas sociais}

Criadas após a Constituição federal de 1988, em decorrência do novo arranjo federativo que atribuía a estados e municípios papéis substantivos na implementação das políticas sociais, ${ }^{17}$ as comissões intergovernamentais reúnem representantes das três esferas de governo para deliberação de aspectos operacionais da implementação de açōes e programas governamentais, na saúde e assistência social. Para a educação, a deliberação restringe-se à definição de pesos financeiros para alocação de recursos do Fundeb.

Essa estratégia de articulação federativa foi utilizada na saúde, em 1991, por recomendação do Conselho Nacional de Saúde, quando foi atribuída à Comissão Intergestores Tripartite (CIT) a função de assessorar o ministro da Saúde em questões relativas à gestão e ao financiamento do SUS (Lucchese et al., 2003). Nas duas décadas posteriores, nos estados, constituíram-se fóruns para expressão das preferências e da deliberação dos governos estaduais e municipais quanto às políticas federais: as chamadas Comissões Intergestores Bipartites (CIB). A Lei n. 12466 de 2011 ratificou a organização dessas comissóes e o Decreto n. 7508, do mesmo ano, previu ainda a organização de Comissões Intergestores Regionais (CIR) para coordenação das regiôes de saúde no interior dos estados. A assistência social, seguindo por mimetismo muitas das escolhas institucionais da saúde, criou, em 1997, figura semelhante de articulação intergovernamental em âmbito federal, com caráter consultivo. No ano seguinte, outra normativa instituiu comissões também nos estados, remodelando o caráter destas para atribuir-lhes caráter deliberativo. Diferentemente da trajetória da saúde, a assistência social organizou, mesmo que formalmente, as comissões intergovernamentais antes mesmo da institucionalização de um "sistema único", cujas diretrizes e operacionalização inicial seriam definidas a partir de 2004. Já na educação a comissão intergovernamental emergiu em 2007, quando foi instituída com representação dos três níveis de governo para discutir três aspectos da implementação do Fundeb: (i) ponderaçôes aplicáveis na distribuição dos recursos; (ii) limites proporcionais de apropriação dos recursos por cada modalidade de ensino; e (iii) parcela de complementação da União. A política pública de educação inovou em sua própria trajetória ao organizar essa instância de pactuação intergovernamental obrigatória, com previsão na Lei n. 11494 de 2007, uma vez que sua organização não previa um "sistema único", como na saúde e na assistência social.

O desenho institucional das comissões inclui elementos congruentes com o federalismo cooperativo, como a composição paritária e a regra do consenso para tomada de decisão, na presunção de relações simétricas entre entes autônomos. Nas três comissões, há uma equivalência entre representantes dos governos federal, estadual e municipal. ${ }^{18} \mathrm{Os}$ dois últimos, em razão do grande número de entes federados, reúnem-se por associações de secretários municipais e estaduais dos respectivos setores de políticas públicas para escolha dos representantes. Essa dificuldade não se apresenta para o governo federal, já que todos falam em nome do mesmo ministério e se posicionam como ator unitário.

As comissões produzem basicamente três tipos de deliberação: apresentações stricto sensu, quando são discutidas temáticas importantes sem criação de 
obrigações ou responsabilidades específicas de implementação; apresentações para pactuação posterior, quando temas são introduzidos para subsidiar decisões sobre novos programas ou ações governamentais; e as pactuações, que são decisões da comissão que normatizam aspectos das políticas setoriais, sejam novas ações governamentais, financiamento federal, regras de organização intergovernamental ou ferramentas de monitoramento e avaliação (Palotti, 2012). Uma vez que as decisōes nacionais requerem concordância dos governos subnacionais, via representaçôes, e estas são tomadas por consenso, conferindo poder de veto a cada membro, estes estariam habilitados a barrar mudanças no status quo para pontos distantes de suas preferências, o que inviabilizaria um conjunto de propostas de políticas públicas, podendo configurar uma "armadilha da decisão conjunta" (Scharpf, 1988). Porém a análise do funcionamento das comissóes entre 2000 a $2011^{19}$ contraria a expectativa de dificuldades insuperáveis para obtenção de consenso na aprovação de pactuações. Pelo contrário, o Gráfico 3 aponta um elevado número de deliberações durante o período analisado, sendo a maior parte relacionada com pactuações ou decisões políticas em que claramente poderia ter havido impedimento por parte de atores insatisfeitos.

As pactuações envolveram aspectos relevantes na organização dos três setores de políticas públicas. Na saúde, destacam-se diversos programas governamentais e de articulação federativa (atenção básica e especializada, assistência farmacêutica e gestão em saúde, além das normas operacionais e o Pacto pela Saúde). Na assistência social, houve estruturação do próprio Sistema Único de Assistência Social (SUAS) por normativas infralegais discutidas e negociadas na CIT e no CNAS, o que envolveu a definição dos novos serviços socioassistenciais, de sistemas de monitoramento e avaliação de programas e de normativas de coordenação intergovernamental. A educação distingue-se por ter havido somente seis pactuações direcionadas a aspectos operacionais específicos do Fundeb, conforme determina a lei de criação da comissão. As comissões também foram espaços privilegiados de discussão das transferências financeiras condicionadas, tratadas na seção anterior. Quase metade das pactuações na saúde e cerca de um terço das pactuações na assistência social, além de todas as seis na educação, envolveram destinação, aplica-

Gráfico 3

Tipo de Deliberações nas Comissóes de Assistência Social, Saúde e Educação - 2000 a 2011

Saúde (2000 a 2011) - Assistência Social (2005 a 2011) - Educação (2008 a 2011)

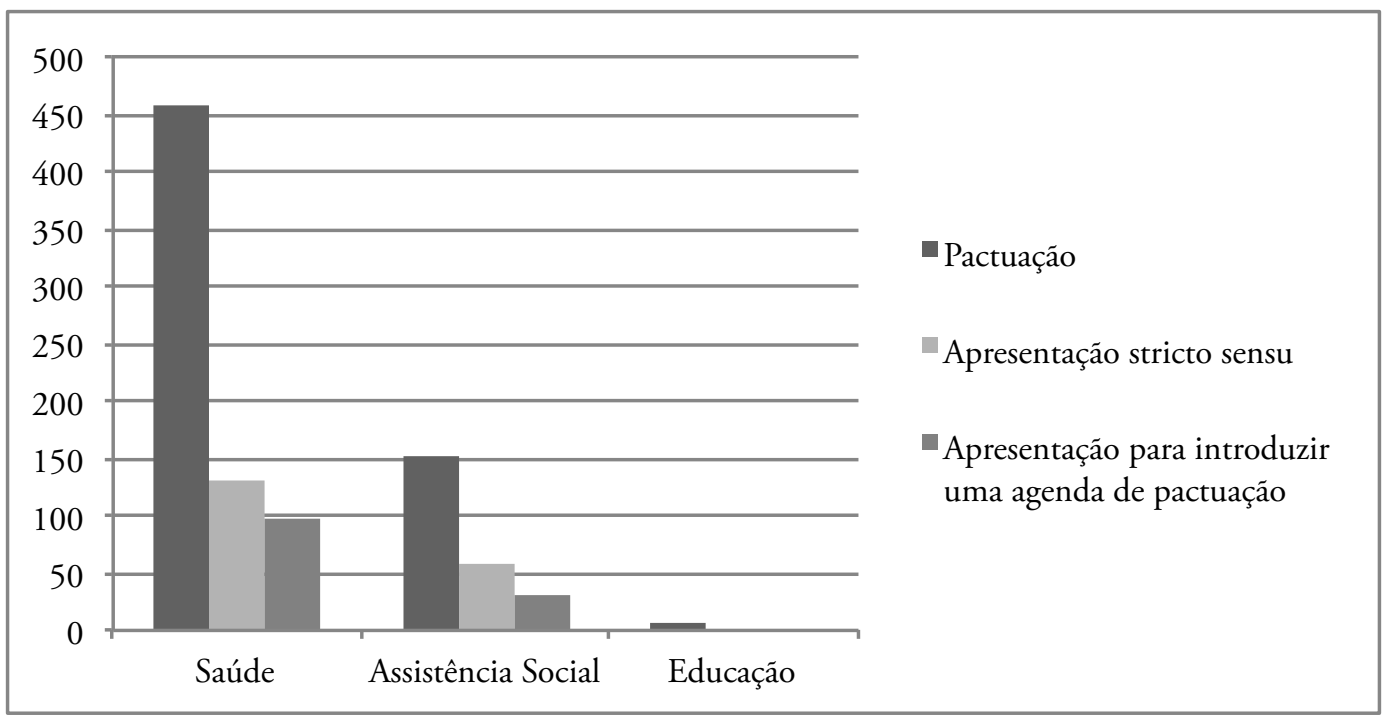

Fonte: Elaboração própria com base em Palotti, 2012. 
ção ou modificação das regras de utilização de recursos financeiros federais.

De especial interesse para este trabalho, observamos que aproximadamente $85 \%$ das proposiçôes se originaram da União, o que sugere elevado poder de agenda deste ator se comparado a estados e municípios. Além disso, conforme podemos antever pelo quantitativo expressivo de pactuações observadas no período analisado, a taxa de sucesso foi também em torno de $85 \%$ das proposições apresentadas, o que mostra eficácia da ação do maior proponente das comissões (Palotti, 2012). Os dados também apontaram para um baixo nível de rejeição das propostas por parte dos atores com poder de veto "afetados" pelas medidas (em regra, estados e municípios). Porém registros elaborados nas reuniōes em plenário permite-nos dizer que as proposições muitas vezes sofreram modificações pelos participantes ou foram rediscutidas em reuniōes posteriores (Idem). Nesses casos, o veto foi preterido em favor de modificações e qualificações que posicionaram decisões finais mais para perto das preferências dos não proponentes - supondo-se que já estariam adequadas para os agenda settlers.

Desse modo, a despeito da composição paritária e da adoção da regra de consenso, parece-nos problemático identificar as arenas deliberação intergestores, ao menos para assistência social e saúde, ${ }^{20}$ como operando tipicamente sob parâmetros do federalismo cooperativo. É perceptível, principalmente no resultado do jogo de forças no interior da comissão, a presença de elementos do federalismo centralizado. Entre as possíveis explicações para esses achados, o poder de agenda assimétrico, com nítido predomínio do Executivo federal, pode ser interpretado como sintoma de problemas de ação coletiva de estados e municípios, muito mais numerosos e heterogêneos. ${ }^{21} \mathrm{O}$ gestor federal mantém relativa discricionariedade para alocação de recursos financeiros, eventualmente mobilizados para indução da aprovação de programas governamentais, tornando a não cooperação custosa para os governos subnacionais, ao adiar ou cancelar o acesso a recursos financeiros e a implementação de novos serviços que poderiam rendar dividendos eleitorais aos políticos locais, ${ }^{22}$ o que sugere níveis relevantes de dependência financeira por parte daqueles go- vernos. Os resultados predominantes, no fim, convergem para a aprovação das proposições da União, ainda que com alteraçôes de forma ou de escopo para sua melhor execução, distanciando-se dos parâmetros definidos anteriormente para o federalismo cooperativo.

$\mathrm{Na}$ próxima seção será abordado um último mecanismo possível para produção de coordenação federativa: as parcerias para gestão compartilhada de políticas públicas.

\section{Consórcios públicos}

A disseminação de associações voluntárias para produção e distribuição de valores entre entes governamentais poderia conferir ao sistema federativo brasileiro um caráter, de fato, cooperativo, em contraste com a própria definição proposta pela ACIR, pautada pelo compartilhamento formal de responsabilidades por uma área de governo. Assim, em que pesem os componentes já apresentados de verticalização do arranjo federativo brasileiro, a presença ampla e autossustentada de consórcios públicos poderia sugerir sua complementação por um componente horizontal. Mas é ainda impreciso constatar se as evidências disponíveis sobre consórcios intergovernamentais fornecem indicações nesta direção ou se, ao contrário, sugerem uma propagação ainda instável e dependente de iniciativas de indução por agentes "externos" ou, ainda, de contextos setoriais específicos.

Admitido em constituições estaduais ${ }^{23}$ no final do século XIX, com a instauração da República, foi na década de 1930 que, em dimensão nacional, o agrupamento de municípios para realização de serviços públicos comuns foi inserido definitivamente no ordenamento jurídico brasileiro. As primeiras experiências bem-sucedidas com consórcios públicos remontam ao interior do estado de São Paulo nos anos de 1960, especialmente em atividades ligadas às áreas de promoção social e desenvolvimento. Mas foi na década de 1980, ainda antes da Constituição federal de 1988, que os consórcios começaram a se disseminar no setor da saúde, onde expandiram-se de maneira intensa nos anos de 1990, chegando a abranger 141 associações distribuídas por treze estados da federação e englobando 1.618 
municípios e 25.376.829 milhões de cidadãos (Lima e Pastrana, 2000). Os consórcios também se disseminaram para outras áreas governamentais nos anos de 1990 e 2000, produzindo experiências que ganharam notoriedade - como a do Consórcio de Penápolis (Ribeiro e Costa, 2000), pelo pioneirismo no setor da saúde, e a do Consórcio da Região do ABC (Cunha, 2004) - sob vários aspectos, como, por exemplo, pela amplitude da sua atuação - políticas sociais, de infraestrutura e de desenvolvimento regional -, mas, principalmente, por ter envolvido uma ampla rede federativa no sentido vertical, incluindo o governo do estado de São Paulo, e horizontal, incluindo também setores da sociedade civil organizada.

Mais recentemente, com a promulgação da Lei n. 11107/2005, também denominada Lei dos Consórcios Públicos, regulamentada por meio do Decreto presidencial n. 6017/2007, houve importante avanço em termos da fixação do marco jurídico para sua constituição. Os consórcios poderiam se constituir como associação pública ou como pessoa jurídica de direito privado, em ambos os casos por meio de contrato e integrando a ad- ministração indireta dos entes consorciados. A Lei previu ainda um protocolo de intençóes entre os entes governamentais participantes, estabelecendo condiçōes para autorizar o consórcio a representá-los, bem como regras para votação nas assembleias gerais. Os consórcios públicos passaram a ter que observar estritamente as normas de direito público nos processos de compra, contratação, prestação de contas, admissão de pessoal e em processos afins. O contrato de rateio tornou-se o mecanismo básico pelo qual os entes consorciados repartiriam os custos da associação para cada exercício financeiro.

Decorrido pouco mais de meia década de sua regulamentação, os efeitos da Lei dos Consórcios se fizeram sentir rapidamente. Publicação recente do Instituto de Pesquisa Econômica Aplicada (Ipea) analisando informações prestadas pelos municípios ao Instituto Brasileiro de Geografia e Estatística IBGE em inquéritos realizados em 2005 e 2009 constatou um "avanço expressivo na quantidade de consórcios públicos” (Ipea, 2010, p. 556), expansão esta percebida "em todas as áreas de atuação, exceto na de transporte" (Idem, p. 563). Tais efeitos foram explicitamente creditados à Lei dos Consórcios:

\section{Gráfico 4}

\section{Participações de Municípios em Consórcios Intermunicipais no Brasil entre 2002 e 2011}

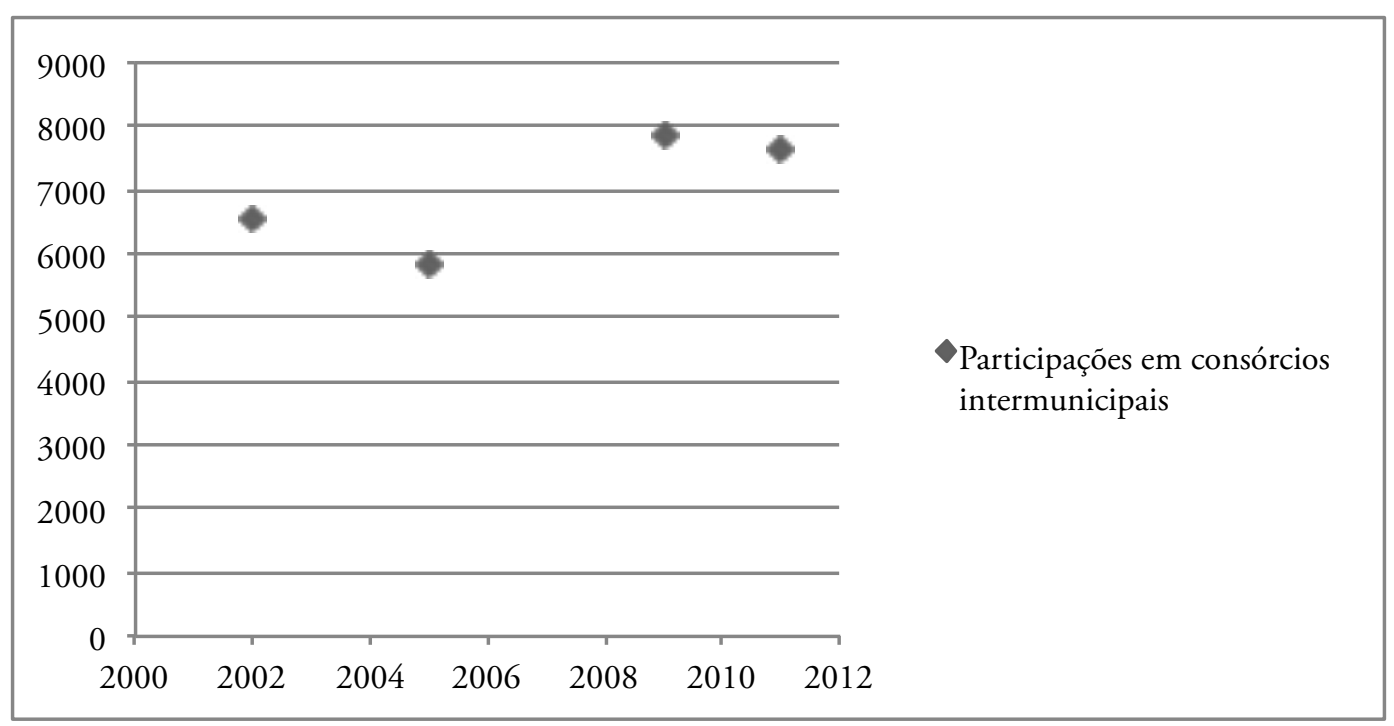

Fonte: IBGE, disponível em http://www.ibge.gov.br/home/estatistica/economia/perfilmunic/. 
Todavia, em que pese o histórico de experiências cooperativas entre entes federados, o arranjo institucional disponível até 2005 tornava frágil qualquer ação, pela precariedade dos mecanismos de enforcement do compromisso assumido pelas partes. Nesse ano, o país passou a ser dotado de uma nova norma legal, que instituiu a figura do consórcio público, para o qual instrumentos mais poderosos de comprometimento dos entes consorciados foram estabelecidos (Idem, p. 563).

Entretanto, a introdução de outros dois levantamentos feitos pelo IBGE, um anterior - para o ano de 2002 - e outro posterior ao período descrito - para 2011 -, levanta dúvidas sobre pelo menos dois aspectos: a continuidade do movimento de expansão e sua presença nas diversas áreas governamentais. O Gráfico 4 apresenta o número de participaçōes em consórcios intermunicipais agregado para nove, entre onze setores pesquisados pelo IBGE, ${ }^{24}$ para os quais o inquérito foi realizado nos quatro anos. Entre 2002 e 2005, em um intervalo de três anos que antecede a Lei dos Consórcios, houve uma redução de $16,2 \%$ nas participaçôes. Entre 2005 e 2009, intervalo de quatro anos, o aumento das participações foi de $53,4 \%$ mas, entre 2009 e 2011, em um intervalo de dois anos, o au-

\section{Gráfico 5}

Participaçóes de Municípios em Consórcios Intermunicipais no Brasil por Setor Governamental entre 2002 e 2011

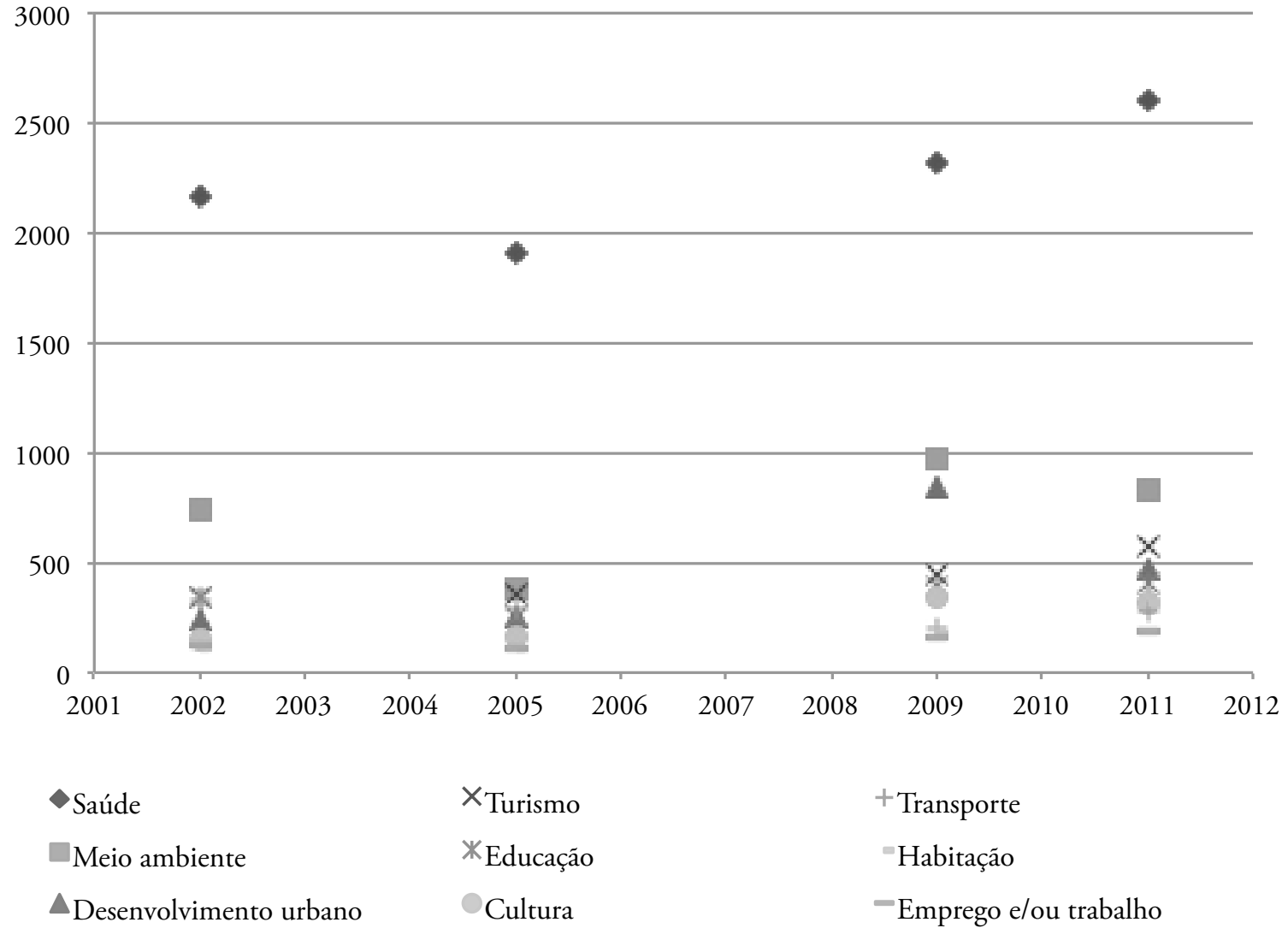

Fonte: IBGE, disponível em http://www.ibge.gov.br/home/estatistica/economia/perfilmunic/. 
mento das participações foi de apenas 2,0\%. O significado desta evolução é ainda incerto e somente inquéritos futuros revelarão se o ciclo de expansão será retomado, se houve uma estagnação no crescimento das participações de municípios ou se elas teriam entrado em um novo ciclo de declínio.

Já o Gráfico 5 sugere que o comportamento dos nove setores ao longo dos quatro inquéritos é bastante variado. Considerando os três intervalos 2002-2005, 2005-2009, 2009-2011 -, em quatro dos nove setores há movimentos de retração/expansão/expansão (e aqui se inclui os setores de saúde e educação ${ }^{25}$ ); em dois há movimentos de expansão/ expansão/retração; em outro há retração/expansão/ retração; em outro, expansão nos três períodos e, em um último setor, retração/retração/expansão. Tal variedade sugere dinâmicas próprias, a despeito do efeito emulador produzido pela Lei dos Consórcios nos primeiros anos de vigência, o que poderia ser explicado pelos efeitos de variáveis endógenas a cada setor.

Pistas importantes sobre fatores endógenos remetem a trabalhos referentes ao setor da saúde, que constataram a forte presença da ação indutora dos governos estaduais, por meio de apoio técnico, jurídico ou, em alguns casos, até mesmo financeiro (Ribeiro e Costa, 2000; Lima e Pastrana, 2000). Se por um lado o setor da saúde responde por mais de $40 \%$ das participações municipais em consórcios em todos os inquéritos realizados pelo IBGE, é notória a intensa concentração de consórcios de saúde entre as unidades federadas: apenas três estados Minas Gerais, Paraná e Mato Grosso - reúnem cerca de $60 \%$ de todos eles, conforme levantamento realizado pelo Ministério da Saúde para 2008. ${ }^{26}$ Nos três estados, os consórcios de saúde foram tomados pelos respectivos governos estaduais como prioridade de ação.

Em 2000, Minas Gerais concentrava setenta dos 141 consórcios de saúde do país, posição explicada pelo apoio logístico, jurídico e político disponibilizado pela Secretaria de Estado da Saúde (Minas Gerais/SES, 1996, 1997). Em 2006, foi criado o Programa de Fortalecimento dos Consórcios Intermunicipais de Saúde, financiando diretamente investimentos de capital, e, em 2009, o Programa Estadual de Cooperação Intermunicipal em Saúde, com financiamento para obras e investimentos, mas também para custeio. ${ }^{27}$ No Paraná, a estratégia para formação da rede regionalizada de atenção a saúde do governo estadual incluiu a estruturação do marco legal para atuação dos consórcios no estado - culminando na Lei complementar n. 82/1998, regulamentada pelo Decreto estadual n. 4514/1998 -, bem como a cooperação técnica para organização dos consórcios. Nos últimos anos o apoio foi ainda mais ostensivo, com a criação do Programa Estadual de Apoio aos Consórcios Intermunicipais de Saúde que, a exemplo do caso mineiro, incluiu incentivos financeiros para investimento e custeio, além de cursos nas áreas de gestão e planejamento para dirigentes de consórcios. Neste caso, a Secretaria de Estado da Saúde, ao reconhecer os consórcios como parte da rede regionalizada de atenção à saúde, induziu sua presença em todas as regiōes de saúde do estado. ${ }^{28}$ Iniciativas semelhantes foram identificadas em Mato Grosso, onde o governo do estado apostou em convênios com os consórcios para cogestão de hospitais estaduais de referência. ${ }^{29}$

Embora não se possa generalizar a presença da indução estadual para outras unidades da federação o que demandaria um estudo sistemático neste sentido - ou, mesmo, para outros setores governamentais, deve-se realçar que os elementos preliminares aqui indicados sugerem esta presença em $60 \%$ dos consórcios no setor governamental que concentra 43\% das participações em consórcios intermunicipais. Além disso, há relatos de experiências recentes de consorciamento induzidas por outros agentes "externos" aos participantes, como federaçóes ou associaçōes de municípios, que, no caso da Federação Catarinense de Municípios (Fecam), patrocinou a formação do Consórcio de Informática na Gestão Pública Municipal (Ciga), reunindo mais de 160 municípios (Abrucio et al., 2013).

Desse modo, as evidências aqui apresentadas sugerem uma presença significativa de arranjos cooperativos entre governos locais no federalismo brasileiro, mas não um caráter autossustentado na estabilização de suas formas institucionais. Pelo contrário, a dependência do Executivo federal em relação à iniciativa de regulamentação gerou dinâmicas setoriais distintas que envolvem movimentos de expansão e retração, bem como a subordinação a 
agentes "externos" - governos estaduais; federações e associaçõos de municípios - para sua sustentação. Portanto, assim como no caso das transferências financeiras condicionadas, a dinâmica das parcerias entre municípios, como os consórcios, terminam por revelar fortes traços de dependência de iniciativas de outras esferas de governo.

\section{Considerações finais}

Neste trabalho enfatizamos que o compartilhamento de responsabilidades sobre uma área governamental em uma constituição federativa não é garantia de que ali se configure um padrão dominante de cooperação intergovernamental. Daí argumentarmos em favor da distinção entre a cooperação como pressuposto adotado em uma norma constitucional e a cooperação de fato, como padrão vigente no campo das relações intergovernamentais. Os problemas de coordenação federativa sob o compartilhamento de responsabilidades também poderiam ser resolvidos a partir do federalismo centralizado, em que governos subnacionais se comportassem como agents da União. Mas como enquadrar a experiência do federalismo brasileiro nessa perspectiva?.

As três políticas sociais aqui abordadas - saúde, educação e assistência social - apresentaram tanto características comuns, quanto aspectos específicos. $\mathrm{Na}$ saúde e na assistência social, o compartilhamento de responsabilidades abrange sistemas nacionais que unificam ou integram as ações do poder público, enquanto na educação o chamado regime de colaboração é restrito à educação básica, convivendo com competências prioritárias a serem exercidas por cada esfera de governo e competências privativas em relação à União. Na saúde e na assistência social optou-se por constituir arenas de pactuação federativa, com pesos de representação iguais para cada esfera de governo e regras decisórias consensuais; na educação, por sua vez, a arena de composição semelhante tem funções bem mais restritas quanto às atribuições e ao alcance das decisões. Nas três áreas, entretanto, o desempenho das políticas sociais depende da articulação das ações emanadas das três esferas de governo.
Se esses elementos, no seu conjunto, apontam em direção ao federalismo cooperativo, há definições constitucionais e legais que operam em outra direção, constrangendo, de um lado, o leque de escolhas dos governos subnacionais encarregados pela implementação das políticas sociais e ampliando, de outro lado, o leque de escolhas da União, dotada de prerrogativas e recursos institucionais especiais para a formulação e a coordenação do processo, assim como para a produção normativa complementar, o controle e, em muitos casos, até mesmo a aplicação de sanções. Estados e municípios são constrangidos a gastarem determinados patamares de seus orçamentos com políticas de saúde e educação e estão sujeitos a critérios uniformes sobre como gastá-los. Além disso, há restrições gerais para gastos com pessoal e endividamento, o que no caso dos governos locais - imbuídos da função de implementação e, diga-se de passagem, absorvedores cruciais da força de trabalho - traz repercussões significativas em relação às demais esferas de governo. A União, com seu destacado papel de formuladora, coordenadora e supervisora do processo das políticas sociais, concentrando, ademais, as receitas públicas nesse sentido, tem poderes normativos diferenciados que afetam a transferência de recursos e responsabilidades entre as esferas de governo, o que lhe permite controlar, auditar e, em muitos casos, punir os desvios do padrão estabelecido nacionalmente ou o uso inadequado de recursos. Esses elementos até podem existir no federalismo cooperativo, mas certamente indicam sua conversão ao federalismo centralizado, uma vez que o poder regulador da União é utilizado para induzir governos subnacionais a se comportarem como "agentes administrativos".

A análise das transferências financeiras condicionadas, largamente utilizadas nas políticas sociais, mostra a aproximação com o modelo de federalismo centralizado ao estruturar a agenda social dos governos subnacionais que, sob restrições do ponto de vista fiscal, aderem aos programas federais no sentido de ampliar a disponibilidade de receitas regulares para fazer face às suas obrigações, mesmo que o condicionamento inclua a convergência sobre o que e como fazer a parâmetros fixados pela burocracia do Executivo federal. 
As arenas de pactuação intergovernamental estruturadas para a gestão compartilhada das políticas sociais, mediante composição paritária e regras decisórias consensuais, também sugerem a convergência para o federalismo cooperativo. Mas, também aqui, a análise das características do processo decisório nessas arenas sugeriu uma nítida diferenciação dos poderes da União não só na sua capacidade de controle da agenda, mas também de induzir apoio a programas federais que sinalizam com novos recursos financeiros, além de outros aspectos, inclusive problemas de ação coletiva a que estão sujeitas as representações de estados e, principalmente, de municípios. Estes, longe de exercerem o poder de veto, preferem nitidamente propor incrementos ou qualificaçôes às propostas da União.

Por fim, a respeito dos consórcios públicos, constatamos significativo crescimento nos primeiros anos após sua regulamentação legal. Entretanto, pelo menos três aspectos chamam atenção: o arrefecimento do ciclo de crescimento nos dados disponíveis mais recentes, a percepção de dinâmicas setoriais bastante distintas em termos de expansão e retração da participação de municípios em consórcios e a forte dependência, sobretudo no caso da saúde, da indução por agentes "externos" aos participantes.

Desse modo, os achados parciais mobilizados neste trabalho, restritos às políticas sociais de saúde, educação e assistência social, sugerem que o regime de compartilhamento de responsabilidades incorpora elementos do federalismo cooperativo - como arenas de pactuação ou parcerias para cooperação -, mas estrutura um amplo espectro de restriçôes constitucionais e legais que amarram a autonomia dos governos subnacionais, bem como recursos institucionais que permitem à União o fortalecimento do seu papel indutor e regulador dos padrões de implementação das referidas políticas, levando os governos subnacionais a assumirem um comportamento próximo ao de agentes administrativos, como ocorre no modelo de federalismo centralizado. As posições assimétricas entre os entes federados parecem afetar os próprios dispositivos do federalismo cooperativo, como, por exemplo, processos decisórios em arenas de pactuação intergovernamental ou as condições para expansão ou manutenção dos consórcios intermunicipais.
Neste trabalho, por uma redução necessária do seu escopo, a análise sobre o caráter assumido pelo federalismo brasileiro nas políticas sociais não incorreu na direção da discussão da sua pertinência. Isto é, não discutimos aqui se a centralização seria justificável ou, mesmo, uma necessidade histórica, já que estamos diante de um país em desenvolvimento, que atravessou um processo de estabilização fiscal recente e que tem buscado alterar o status quo no que se refere às profundas desigualdades sociais e regionais. Isto não significa, a nosso ver, uma desvalorização desta questão, mas apenas o entendimento de que não está ainda vencido o debate acerca do caráter de nosso federalismo pós-1988.

Por fim, a percepção do peso diferenciado dos traços centralizadores no exercício das funções compartilhadas entre esferas de governo em políticas sociais não constitui novidade na literatura política, tendo apoio em trabalhos como os empreendidos por Almeida (2005), Souza (2005) e, particularmente, no trabalho de Arretche (2012). Também termina por convergir para estudos políticos mais abrangentes que - como no caso dos estudos legislativos - realçam os efeitos produzidos pelas capacidades e recursos institucionais concentrados no Executivo federal (Figueiredo e Limongi, 1999; Santos, 2003). Não obstante, o que aqui se buscou foi explorar o argumento de que a presença de tais capacidades e recursos centralizadores também atravessa o conjunto de mecanismos de coordenação federativa.

\section{Notas}

1 Exemplos neste sentido são a Lei complementar n. 140 de 2011, referente à área ambiental; a Lei de Responsabilidade Fiscal, que restringiu a gestão fiscal dos entes federados, e a regulamentação da Emenda constitucional n. 29, pela Lei complementar n. 141 de 2012, para o financiamento da saúde.

2 Advisory Commission on Intergovernmental Relations, agência independente e bipartidária que foi instituída pelo Congresso Norte-Americano em 1959 para estudar e propor recomendações envolvendo as relaçôes intergovernamentais nos Estados Unidos, tendo sido extinta em 1996. 
3 No original, "most importantly, cooperative federalism lacked the prescriptive power of dual federalism. It offered no rationale for assigning of intergovernmental functions or for directing governmental growth. Cooperative federalism prescribes only intergovernmental 'sharing' [...]" (p. 4).

4 Scharpf faz as devidas ressalvas às mudanças em curso em termos de intensificação de superposições de atuação entre governos de diferentes esferas no caso norte-americano, o que remete, por sua vez, aos anos de 1930, notadamente a ajustes operados a partir do New Deal (Wright, 1974).

5 Consideramos aqui a definição de cooperação proposta por Axelrod e Keohane no trato das relaçôes intergovernamentais no plano internacional "cooperatiion is not equivalente to harmony. Harmony requires complete identity of interests, but cooperation can only take place in situations that contain a mixture of confliting and complementary interests. In such situations, cooperation occurs when actors adjust their behavior to the actual or anticipated preferences or others" (1985, p. 226).

6 A literatura em ciência política aponta ainda um conjunto de ações interconectadas, mas não necessariamente coordenadas (Simmons e Elkins, 2005), de difusão de inovações governamentais entre países ou unidades subnacionais. Segundo Rogers, difusão pode ser caracterizada como "o processo pelo qual (1) uma inovação (2) é comunicada por certos canais (3) ao longo do tempo (4) entre os membros de um sistema social" (2003, p. 11, tradução nossa). No Brasil, estudos recentes têm apontado a importância de tais mecanismos de aprendizagem e emulação entre os entes federados para adoção de novos programas governamentais (Coelho, 2012; Coelho et al., 2012). Como estamos tratando de mecanismos de coordenação intergovernamental, essas pesquisas não serão observadas neste momento, não obstante, em futuros trabalhos, seus achados possam ser combinados às evidências indicadas aqui.

7 Este, por sua vez, corresponderia ao nível de gasto realizado em 1999 acrescido de 5\%. Esse critério deveria vigorar até 2004 , tendo sido mantido posteriormente e perpetuado com a Lei complementar $\mathrm{n}$. $141 / 2012$, que regulamentou a Emenda constitucional n. 29/2000.

8 O Conselho Nacional de Saúde havia fixado parâmetros para caracterizar os gastos com área desde 2003, por meio da Resolução 322, mas esta constituiu apenas uma referência para apuração de gastos, ainda sem efeito legal.
9 Dados do Sistema de Informaçōes sobre Orçamentos Públicos em Saúde (Siops), para 2012, dão conta que $45,57 \%$ das despesas com saúde se destinavam a gasto com pessoal no conjunto dos municípios brasileiros, enquanto no conjunto dos estados estes percentual era de $27,04 \%$.

10 A desvinculação das receitas da União foi implantada em 1994, por meio do Fundo Social de Emergência (FSE), criado por ocasião do Plano Real, tendo sofrido alterações em 1996, inclusive na denominação para Fundo de Estabilização Fiscal (FEF), e posteriormente, em 2000, quando assumiu o nome Desvinculação de Receitas da União (DRU).

11 Diferentemente das obrigatórias, transferências discricionárias são repassadas "a estados e municípios sem vinculação a nenhum dispositivo legal que determine rigidamente o montante, bem como o momento da realização do dispêndio" (Brasil/Ministério do Planejamento, Orçamento e Gestão, 2010, p. 53).

12 As obrigatórias passaram de $\mathrm{R} \$ 19.372,20$ para $\mathrm{R} \$$ 137.350,2 milhões enquanto as discricionárias para políticas sociais passaram de $\mathrm{R} \$ 2.767,48$ para $\mathrm{R} \$ 42.839,92$ milhōes, segundo dados da Secretaria de Orçamento Federal do Ministério do Planejamento Orçamento e Gestão (Machado, 2011).

13 Tomamos esta definição emprestada de Marta Arretche (2009), que a utiliza para se referir ao fato de que todos governos subnacionais que cumpram os requisitos gerais estabelecidos em norma federal estariam habilitados a recebê-las.

14 Estes disciplinam a transferência e a utilização de recursos públicos da União por um governo subnacional, visando à realização de programas, projetos e atividades de interesse recíproco, com duração definida e em regime de cooperação mútua (Brasil/Senado federal, 2005).

15 Instrumentos para transferir recursos da União para governos subnacionais por intermédio de instituiçōes ou agências financeiras federais para execução de programas governamentais (Brasil/Senado federal, 2005).

16 No campo das relações intergovernamentais, tais relações conferem à União o papel de principal e aos governos subnacionais o de agent. Assumem, assim, formato similar a um contrato em que a primeira define metas e remunera os últimos para executá-las.

17 Notadamente a partir do governo Lula, houve um movimento de redefinição dos canais de interlocução federativa, marcado pela ascensão da esfera municipal. A criação do Ministério das Cidades, do Comitê de Articulação Federativa, com representação da União e associaçōes e federaçôes que representam municípios, é 
parte deste movimento que, em grande medida, converge para a intensificação do padrão centralizado no federalismo brasileiro pós-1988. Entretanto, a opção por nos restringir setorialmente a três áreas governamentais deixou este importante componente ao largo de nossa análise, embora reconheçamos que eventuais comprometimentos analíticos possam decorrer daí.

18 Nas comissões da saúde e da assistência social, a representação das esferas federal, estadual e municipal é de sete e cinco membros, respectivamente, para cada esfera de governo. $\mathrm{Na}$ educação, estão previstos cinco representantes para estados e municípios e somente um representante para o governo federal, o que não prejudica seu poder de veto.

19 Somente os dados da CIT-Saúde estavam disponíveis para todo o período. A CIT-Assistência Social possuía dados somente entre 2005 e 2011 e a Comissão do Fundeb possuía dados somente a partir de 2008, quando foi iniciado seu funcionamento.

20 A Comissão do Fundeb é mais restritiva em seu escopo, principalmente em razão dos mandamentos legais para sua organização e funcionamento, que limitam seu escopo de atuação.

21 Segundo Palotti e Machado (2014), além das vantagens usufruídas pela União na interação com estados e municípios no âmbito das comissões, outras hipóteses explicativas poderiam ser apontadas: a organização institucional das comissões (como a existência de câmaras de pré-processamento dos acordos); o formato da produção normativa (portarias ministeriais de caráter menos vinculatório que normas legais e constitucionais) e a convergência para um mesmo conjunto de preferências, valores ou concepçôes, no sentido de identidades comuns entre os gestores das políticas sociais estudadas, perpassando inclusive, mas não unicamente, pelo alinhamento político-partidário.

22 Embora relevante, o papel das transferências financeiras não deve ser superestimado, tendo Palotti (2012) identificado pactuações deste tipo que foram modificadas ou rejeitadas, principalmente quando envolveram outros aspectos conflituosos.

23 Cunha (2004) lembra que o artigo 56 da Constituição paulista de 1891 já previa a associação de municipalidades para realização de melhoramentos de interesse comum, porém condicionada à aprovação do Legislativo estadual.

24 Ficaram de fora, portanto, o setor de assistência e desenvolvimentos social, que não participou do inquérito de 2009, e o de saneamento básico, que não participou dos de 2002 e 2009.
$25 \mathrm{Na}$ assistência social não há dados para 2009. Houve retração entre 2002 e 2005 e expansão entre este último ano e 2011.

26 Levantamento realizado pelo Departamento de Apoio à Descentralização (DAD) para a Comissão Intergestores Tripartite (CIT), referente à situação de junho de 2008.

27 Editais da Secretaria de Estado foram lançados nos anos de 2008, 2009 e 2010, oferecendo a oportunidade para que os consórcios elaborassem projetos para concorrer aos recursos. Editais e informações adicionais estão disponíveis em http://www.saude.mg.gov.br/.

28 Informações sobre o programa estão disponíveis em http://www.sesa.pr.gov.br/modules/conteudo/conteudo.php? conteudo $=2890$.

29 Disciplinado pela Instrução normativa 01/2010 editada conjuntamente pela Secretaria de Planejamento, Secretaria de Fazenda, Secretaria de Saúde e Advocacia Geral do Estado do Mato Grosso, disponível em http://www.seplan.mt.gov.br/sigcon/index_. php?operacao $=$ Exibir\&serv $=$ legis $/$ legislacao \&grupo $=i$ n\&lei=IN_01_10.

\section{BIBLIOGRAFIA}

ABRUCIO, F. L. (2005), "A coordenação federativa no Brasil: a experiência do período FHC e os desafios do governo Lula". Revista de Sociologia e Politica, 24: 31-67.

ABRUCIO, F. L.; FILIPPIM, E. S. \& DIEGUEZ, R. C. (2013), "Inovação na cooperação intermunicipal no Brasil: a experiência da Federação Catarinense de Municípios (Fecam) na construção de consórcios públicos”. Revista de Administração Pública, 47 (6): 1543-1568.

ACIR - Advisory Commission on Intergovernmental Relations. (1981), "The condition of contemporary federalism: conflicting theories and collapsing constraints". Washington, UNT. Disponível em http://digital.library.unt. edu/ark:/67531/metadc1339/, consultado em $14 / 12 / 2012$

ALMEIDA, M. H. T. (2000), "Federalismo e proteção social: a experiência brasileira em perspectiva comparada". Trabalho apresentado no Seminário Pacto Federativo e Guerra Fiscal no Brasil. São Paulo, FGV. 
(2005), "Recentralizando a federação?". Revista de Sociologia e Politica, 24: 29-40.

. (2007), "O Estado no Brasil contemporâneo: um passeio pela história", in, C. R. Melo e M. A. Sáez (orgs.), A democracia brasileira: balanço e perspectivas para o século 21, Belo Horizonte, Editora UFMG, pp. 17-37.

ARRETCHE, M. (1999a), "Políticas sociais no Brasil”. Revista Brasileira de Ciências Sociais, 14 (40): 111-141.

(1999b), "Mitos da descentralização: mais democracia e eficiência nas políticas públicas?". Revista Brasileira de Ciências Sociais, 11 (31): 44-66.

(2004), Federalismo e políticas sociais no Brasil: problemas de coordenação e autonomia”. São Paulo em Perspectiva, 18 (2): 17 26.

(2009), "Continuidades e descontinuidades da federação brasileira: de como 1988 facilitou 1995”. Dados, 52 (2): 377-423. . (2010), "Federalismo e igualdade territorial: uma contradição em termos?”. Dados, 52 (3): 587-620.

. (2012), Democracia, federalismo e centralização no Brasil. Rio de Janeiro, FGV/Fiocruz. AXELROD, R. \& KEOHANE, R. O. (1985), "Achieving cooperation under anarchy: strategies and institutions". World Politics, 38 (1): 226-254.

BRASIL. (1988), Constituição da República Federativa do Brasil de 1988. Disponível em http:// www.planalto.gov.br/ccivil_03/Constituicao/ Constituicao.htm, consultado em 17/12/2012. . (1990), "Lei n. 8080, 19 set. Dispõe sobre as condiçôes para a promoção, proteção e recuperação da saúde, a organização e o funcionamento dos serviços correspondentes e dá outras providências". Disponível em http://portal.saude.gov.br/portal/arquivos/pdf/LEI8080. pdf, consultado em 12/7/2006.

(2005), "Lei n 11107, 6 abr. Dispõe sobre normas gerais da contratação de consórcios públicos e dá outras providências". Disponível em https://www.planalto.gov.br/ccivil_03/_ Ato2004-2006/2005/Lei/L11107.htm, consultado em 12/7/2006.
(2010), "Ministério do Planejamento, orçamento e gestão". Séries Históricas de Dados e Indicadores Fiscais. Brasília, MPOG.

BRASIL/Senado Federal. (2005), "Manual para obtenção de recursos federais para municípios sem intermediação de terceiros: orientação aos prefeitos". 5 ed. Brasília, Senado federal. Disponível em http://www.senado.gov.br/sf/senado/ilb/asp/PR_Consulte_ConsulteManual. asp, consultado em 9/9/2011.

BRASIL / Tesouro Nacional. (2012), "Relatório de gestão fiscal do poder Executivo federal $-3^{\circ}$ Quadrimestre de 2012". Disponível em http:// www3.tesouro.fazenda.gov.br/hp/downloads/ lei_responsabilidade/RGF2Q2012.pdf, consultado em 26/12/2013.

BROSCHEK, J. (2007), "Federalism and political change: Germany and Canada in historical-institutionalist perspective". Trabalho apresentado em Annual Meeting of the Canadian Political Science Association, University of Saskatchewan, Saskatoon. Disponível em http://www.uni-augsburg.de/institute/kanada/ pdf-files/Saskatoon_Federalism_Final_Mai07. pdf, consultado em 16/12/2012.

COELHO, D. B. (2012), "Political competition and the diffusion of conditional cash transfers in Brazil". Brazilian Political Science Review, 6: 56-87.

COELHO, D. B.; TURGEON, M. \& CAVALCANTE, P. (2012), "Mecanismos de difusão de políticas sociais no Brasil: uma análise do Programa de Saúde da Família". Anais do VIII Encontro da Associação Brasileira de Ciência Politica. Gramado.

CUNHA, R. E. (2004), "Federalismo e relaçôes intergovernamentais: os consórcios públicos como instrumento de cooperação federativa". Revista do Serviço Público, 55 (3): 5-34, Escola Nacional de Administração Pública.

FRANZESE, C. (2010), Federalismo cooperativo no Brasil: da Constituição de 1988 aos sistemas de políticas públicas. São Paulo, tese de doutorado, Escola de Administração de Empresas de São Paulo. FIGUEIREDO, A. \& LIMONGI, F. (1999), Executivo e Legislativo na nova ordem constitucional. Rio de Janeiro, FGV. 
IPEA. (2010), Brasil em desenvolvimento: Estado, planejamento e politicas públicas. Brasília, Ipea.

LIMA, A. P. G. \& PASTRANA, R. (2000), "Relatório de pesquisa: diagnóstico da situação atual de consórcios intermunicipais de saúde no Brasil”. Brasília, Opas.

LUCCHESE, P. T. R.; NASCIMENTO, A; COHEN, M. M.; VASCONCELOS, M. M. \& GARCIA, M. (2003), A gestão compartilhada do Sistema Único de Saúde no Brasil: o diálogo na comissão intergestores tripartite. Rio de Janeiro, Fundação Oswaldo Cruz.

LÜFLER, E. (2000), "A gestão da responsabilização nas parcerias intergovernamentais". Revista do Serviço Público, 51 (2): 5-33, Escola Nacional de Administração Pública

MACHADO, J. A. (2008), "Gestão de políticas públicas no Estado federativo: apostas e armadilhas". Dados, 51 (2): 433-457.

(2011), "Relatório de pesquisa: relações intergovernamentais e coordenação de políticas sociais: eficácia e contenção do poder no desenho dos incentivos financeiros federais". Belo Horizonte, UFMG/CNPq/Fapemig.

MELO, M. A. (2005), "O sucesso inesperado das reformas de segunda geração: federalismo, reformas constitucionais e política social". $D a-$ dos, 48 (4): 845-889.

MINAS GERAIS/Secretaria de Estado da Saúde. (1996), "Componente desenvolvimento de consórcios intermunicipais de saúde". Belo Horizonte, SES/MG.

(1997), "Consórcio intermunicipal de saúde”. Belo Horizonte, SES/MG.

NESP/CEAM/UnB. (2006), "Despesa com pessoal e lei de responsabilidade fiscal: uma análise da situação na União, nas unidades federadas e nos municípios”. Brasília. Disponível em http://www.observarh.org.br/nesp, consultado em 25/2/2013.

OATES, W. E. (1999), "An essay on fiscal federalism". Journal of Economic Literature, 37 (3): 1120-1149.

OBINGER, H. et al.. (2005), Federalism and the Welfare State: new world and European experiences. Nova York, Cambridge University.
PALOTTI, P. (2012), Coordenação federativa e a "armadilha da decisão conjunta": as comissões de articulação intergovernamental das políticas sociais no Brasil. Belo Horizonte, dissertação de mestrado, UFMG.

PALOTTI, P. \& MACHADO, J. A. (2014), "Coordenação federativa e a "armadilhada decisão conjunta": as comissões de articulação intergovernamental das políticas sociais no Brasil". Dados, 57 (2): 399-441.

REZENDE, F. \& AFONSO, J. R. R. (2004), “A federação brasileira: fatos, desafios e perspectivas", in F. Rezende e F. A. Oliveira (orgs.), Federalismo e integração econômica regional: desafios para o Mercosul, Rio de Janeiro, Konrad Adenauer, pp. 301-362.

RIBEIRO, J. M. \& COSTA, N. R. (2000), "Regionalização da assistência à Saúde no Brasil: os consórcios municipais no Sistema Único de Saúde”. Planejamento e Políticas Públicas, 22: 173-220.

ROGERS, Everett M. (2003), Diffusion of innovations. 5 ed. Nova York, Free Press.

SANTOS, F. (2003), O poder Legislativo no presidencialismo de coalizão. Belo Horizonte/Rio de Janeiro, Editora UFMG/Iuperj.

SCHARPF, F. W. (1988), “The joint-decision trap: lessons from German federalism and European integration". Public Administration, 66 (3): 239-278.

SIMMONS, B. A. \& ELKINS, Z. (2005), "On waves, clusters and diffusion: a conceptual framework". Annals of the American Academy of Political and Social Science, 598: 33-51.

SOUZA, C. (2005), Federalismo, desenho constitucional e instituições federativas no Brasil pós-1988”. Revista de Sociologia e Política, 24: 105-121.

WRIGHT, D. S. (1974), "Intergovernmental relations: an analytical overview". Annals of the American Academy of Political and Social Science, 1 (416): 1-16. 


\section{ENTRE COOPERAÇÃO \\ E CENTRALIZAÇĀO: \\ FEDERALISMO E POLÍTICAS \\ SOCIAIS NO BRASIL PÓS-1988}

José Angelo Machado e

Pedro Lucas de Moura Palotti

Palavras-chave: Federalismo, cooperação, federalismo, relações intergovernamentais, políticas sociais

Neste trabalho analisamos evidências empíricas relativas às relações intergovernamentais nas principais áreas de políticas sociais - saúde, educação e assistência social - com propósito de avaliar em que medida elas seriam ou não consistentes com parâmetros típicos de um federalismo descentralizado e cooperativo. Ao final concluímos que, a despeito do compartilhamento de competências entre esferas de governo no plano jurídico-legal, o padrão de relações intergovernamentais consolidado duas décadas e meia após a Constituição Federal de 1988 é marcado fundamentalmente pela verticalização, atuando a União como formuladora e indutora das políticas e programas sociais implementados pelos governos subnacionais, do que resultam características bem mais próximas do federalismo centralizado.

\section{BETWEEN COOPERATION AND CENTRALIZATION: FEDERALISM AND SOCIAL POLICIES IN POST-1988 BRAZIL}

\section{José Angelo Machado e Pedro Lucas de Moura Palotti}

Keywords: Federalism; Cooperation; Intergovernmental relations; Social policies

The article analyzes empirical evidence concerning intergovernmental relations in key areas of social policy - health, education and social care - with the purpose of assessing whether or nor they would be consistent with typical parameters of a decentralized and cooperative federalism. The analysis concludes that, despite the sharing of powers between levels of government in juridical and legal terms, the pattern of intergovernmental relations consolidated two and a half decades after the 1988 Constitution is primarily marked by vertical integration, the Union acting as formulator and inductor of social policies and programs implemented by subnational governments, resulting in characteristics much closes to a centralized federalism.

\section{ENTRE COOPÉRATION ET CENTRALISATION: LE FÉDÉRALISME ET LES POLITIQUES SOCIALES AU BRÉSIL POST-88}

\author{
José Angelo Machado e \\ Pedro Lucas de Moura Palotti
}

Mots-clés: Fédéralisme; Coopération; Relations intergouvernementales; Politiques sociales

Dans ce travail, nous analysons les données empiriques concernant les relations intergouvernementales dans des domaines clés de la politique sociale - santé, éducation et protection sociale - dans le but de déterminer si elles seraient compatibles avec des paramètres typiques d'un fédéralisme décentralisé et coopératif. Nous concluons que, malgré le partage des pouvoirs entre les niveaux de gouvernement sur les plans juridique et légal, le modèle de relations intergouvernementales consolidé 25 ans après l'entrée en vigueur de la Constitution de 1988 est principalement marqué par l'intégration verticale, l'Union européenne agissant en tant que formulatrice et inductrice de politiques et de programmes sociaux mis en œuvre par les gouvernements infranationaux. Cela résulte en des caractéristiques beaucoup plus proches du fédéralisme centralisé. 